\title{
As vivências do desemprego entre trabalhadores no interior do Rio Grande do Norte
}

\author{
Fellipe Coelho-Lima ${ }^{\mathrm{I}, 1}$, Matheus Rodrigo Confessor Teixeira ${ }^{\mathrm{II}, 2}$, \\ Katiane Leite da Silva Lima ${ }^{\mathrm{II}, 3}$ e Anne Louyse Gomes de Medeiros ${ }^{\mathrm{II}, 4}$ \\ ${ }^{\text {I } U n i v e r s i d a d e ~ F e d e r a l ~ d o ~ R i o ~ G r a n d e ~ d o ~ N o r t e ~(N a t a l, ~ R i o ~ G r a n d e ~ d o ~ N o r t e, ~ B r a s i l) ~}$ \\ ${ }^{\text {II }}$ Universidade Federal do Rio Grande do Norte (Santa Cruz, Rio Grande do Norte, Brasil)
}

\begin{abstract}
O desemprego tem se tornado foco constante de estudos desenvolvidos pela psicologia, mas o contexto interiorano é pouco explorado. Objetivou-se analisar a vivência do desemprego entre trabalhadores em um município interiorano, considerando os significados atribuídos ao trabalho e desemprego, crenças, sentimentos e estratégias de enfrentamento. Foram realizadas entrevistadas semiestruturadas com sete mulheres e três homens, com idade entre 20 e 55 anos e tempo de desemprego entre um mês e 20 anos. Foi possível identificar que a crença do desemprego pode ser atribuída às causalidades externas e o trabalho significado como sobrevivência. Os afetos são ambíguos e as principais estratégias de sobrevivência são a realização de trabalhos informais e dependência do auxílio financeiro da família. Para superar o desemprego, os entrevistados distribuem currículos e realizam capacitação. Conclui-se que há semelhanças entre aspectos das vivências do desemprego interioranos, identificados neste estudo, e outros que focalizaram trabalhadores em grandes centros, se diferenciando no pouco recurso às políticas públicas e aos círculos sociais como forma de superar o desemprego.
\end{abstract}

Palavras-chave: Desemprego, Vivências, Enfrentamento ao desemprego, Sentido do trabalho.

The Experiences of Unemployment among Workers in Rio Grande do Norte's countryside

The unemployment has been an ongoing focus of recent studies in the field of psychology, but the context of countryside regions is less explored. This article aims to analyze the unemployment experience of workers in a countryside city, taking into consideration how work and unemployment are signified, beliefs, feelings, and coping strategies adopted. Semi-structured interviews were conducted with seven women and three men, between 20 and 55 years of age, with unemployment time ranging between one month and 20 years. It was possible to identify the belief that unemployment can be attributed to external causes, and work signified as survival. Feelings towards them are ambiguous, and the main survival strategies are resorting to informal work and relying upon financial aid from the family. In order to overcome unemployment, respondents send out curriculum and invest in professional qualification. It is possible to conclude that there are similarities between some of the aspects around unemployment experiences in the countryside identified in this study, and others that focus on workers in large urban centers, with the difference of lower investments in public policies and social circles as a way to overcome unemployment.

Keywords: Unemployment, Experiences, Confronting unemployment, Meaning of work.

\footnotetext{
${ }^{1}$ Departamento de Psicologia. http://orcid.org/0000-0001-7763-4050

${ }^{2}$ Faculdade de Ciências da Saúde do Trairí. http://orcid.org/0000-0002-1277-1668

${ }^{3}$ Faculdade de Ciências da Saúde do Trairí. http://orcid.org/0000-0001-5907-490X

${ }^{4}$ Faculdade de Ciências da Saúde do Trairí. http://orcid.org/0000-0002-7673-5340
} 


\section{Introdução}

s taxas de desemprego, no Brasil têm se elevado desde a recessão econômica de 2012. Os
dados da Pesquisa Nacional por Amostra de Domicílios (Instituto Brasileiro de Geografia e Estatística: IBGE, 2019) apontam que o país encerrou o primeiro semestre de 2019 com $12,7 \%$ de pessoas desempregadas. Números menores que nos dois últimos anos, mas elevados em relação à última década, em que o Brasil conviveu com índices de um dígito relativos ao desemprego (IBGE, 2019).

Partindo de uma perspectiva marxista, o desemprego é um fenômeno orgânico do capitalismo, por colaborar com o processo de acumulação de capital, por, ao menos, duas razões. Uma é que a elevação no número de trabalhadores desempregados, ou exército de reserva, pressiona os preços dos salários para baixo, pois aqueles que não possuem remuneração - bem como aqueles que estão nos postos de trabalho - se submetem a condições de trabalho piores para poder receber algum rendimento mínimo (Marx, 1867/2013). A segunda razão é que, quando na situação de desempregado, há a tendência de os trabalhadores se desvincularem dos seus organismos coletivos, passando a conceber os demais trabalhadores na mesma condição como rivais, não mais como companheiros (Mandel, 1972/1982). Dessa forma, o desemprego colabora, por um lado, para o barateamento da compra da força de trabalho e, por outro, para o enfraquecimento da luta política dos trabalhadores.

O desemprego é uma condição geral do sociometabolismo capitalista, mas se manifesta de formas diversas em cada contexto histórico-social. Portanto, há períodos em que ele está minimizado - como houve em alguns países que passaram pela experiência do Estado de BemEstar Social (Nogueira, 2001) - ou maximizado. O último cenário tornou-se mais comum ao redor do mundo após a década de 1970, com o advento da reestruturação produtiva (Antunes, 1999) e a crise econômica mundial de 2008 (Harvey, 2011).

Ao mesmo tempo em que se configura como um fenômeno socioeconômico-cultural, o desemprego também abarca uma dimensão psicossocial (Leão et al., 2006; Mandelbaum \& Ribeiro, 2017). Isto é, a vivência do desemprego causa profundos impactos em diversos aspectos da vida dos trabalhadores, como sua saúde mental, renda, relacionamentos sociais, arranjos familiares, autoestima, entre outros (Álvaro-Estramiana et al., 2012; Furnham, 2013; Kahn, 2013; Lima \& Gomes, 2010; Moyano-Díaz, Gutiérrez Peña, Zúñiga, \& Cornejo, 2013; Schmitz, 2011).

A Psicologia brasileira tem colaborado com investigações acerca dos efeitos do desemprego sobre o trabalhador, destacando-se duas linhas de estudos: relacionadas ao estado da saúde mental dos trabalhadores desempregados e às experiências dos sujeitos nessa situação. Nessa última frente, mais especificamente, têm se destacado as pesquisas acerca dos afetos dos trabalhadores desempregados, os sentidos e significados atribuídos ao trabalho e ao desemprego, o processo de enfrentamento dessa situação e as crenças acerca dos motivos de estar desempregado (Coelho-Lima, Costa, \& Bendassolli, 2013).

Conquanto essas investigações da Psicologia tenham ajudado a revelar uma dimensão por muitas vezes abandonada acerca do desemprego, elas também possuem limitações significativas. Como apresentam Coelho-Lima et al. (2013), essas investigações têm como 
público os trabalhadores desempregados oriundos das capitais e centros econômicos do eixo Sul-Sudeste do país. Portanto, pouco se sabe sobre os efeitos do desemprego para os trabalhadores no interior do Brasil. Essa diferenciação é importante, pois, no primeiro caso dos residentes em cidades desenvolvidas, de grande e médio porte -, há a presença de uma estrutura econômica (e, consequentemente, de formalização do mercado de trabalho) e de investimentos públicos (que redundam em serviços de apoio aos trabalhadores desempregados) distantes daqueles existentes nos municípios com menor desenvolvimento. Se, por um lado, as pesquisas na área acabam não abarcando essas outras realidades, por outro, cerca de $55 \%$ da população brasileira reside em municípios fora das regiões metropolitanas com mais de um milhão de habitantes (IBGE, 2016).

Diante disso, o presente artigo tem por objetivo caracterizar a vivência do desemprego por trabalhadores em um município interiorano. Para tanto, serão abordados quatro aspectos específicos dessas vivências, quais sejam: afetos relativos à situação de desemprego, os sentidos e significados atribuídos ao trabalho e ao desemprego, o processo de enfrentamento dessa situação e as crenças acerca dos motivos do desemprego. A escolha dessas dimensões justificase como: 1) são as que comumente a Psicologia tem abordado nos estudos com as populações nas grandes cidades (Coelho-Lima et al., 2013), o que permite, por meio de comparações indiretas, evidenciar as especificidades da vivência no desemprego de trabalhadores em cidades de menor porte; 2) a partir do referencial da Psicologia Histórico-Cultural, essas são dimensões pertinentes à compreensão da vivência humana diante de situações dramáticas.

\section{Vivência dos trabalhadores desempregados}

Se, do ponto de vista histórico, social, econômico e cultural, esta pesquisa é informada pela literatura marxista, para a compreensão da dimensão psicossocial recorre-se a Vygotsky, considerando a filiação ontoepistemológica ao marxismo desse autor (Carmo \& Jimenez, 2013; Prestes \& Tunes, 2012; Santa \& Baroni, 2014).

Considerando alguns aspectos que os estudos sobre o desemprego vêm colocando como, por exemplo, a sua capacidade de figurar como um rompimento biográfico e de subjetividade semelhante (Ribeiro, 2007) -, é possível caracterizá-lo como uma situação dramática. Isto é, uma situação em que o sujeito é confrontado por um impedimento da realidade para a realização de seu desejo (Delari Jr, 2011; Vygotsky, 1986/2000), qual seja, o de continuar trabalhando, quando se trata de desemprego involuntário. Por sua vez, essas situações promovem uma ampla mobilização do arcabouço psicológico dos sujeitos, no intento de superar o conflito presente. Como consequência dessa intensa atividade, tais vivências podem resultar em processos amplos ou restritos de desenvolvimento, ou seja, de saltos qualitativos no estado atual das funções psicológicas superiores e da personalidade dos sujeitos em sua totalidade ou em aspectos específicos (Veresov, 2016). Como destacam Toassa e Sousa (2010), são inerentes a essas vivências não apenas uma mobilização cognitiva, do modo como a pessoa representa o mundo ou um elemento específico, mas também uma intensa ativação volitivo-afetiva.

Outras investigações acerca do desemprego já têm buscado fundamentos nas teses vygotskyanas, como Leão et al. (2006), Leão, Souza e Silva (2015) e Furtado (1999). De 
maneira geral, os achados dessas investigações sugerem uma mudança de consciência dos trabalhadores em situação de desemprego, apontando novas formas de se apropriarem do mundo e de atuarem sobre ele. $\mathrm{O}$ que tais investigações apontam é a presença de mediadores, como a família, o sindicato e mesmo os discursos socialmente compartilhados na elaboração da realidade por parte dos trabalhadores desempregados.

Seguindo essa compreensão, é razoável afirmar ser possível investigar a vivência dos trabalhadores desempregados pelo modo como compreendem a sua situação - os sentidos ${ }^{5}$ atribuídos ao trabalho e as crenças que elaboram sobre as razões de estarem desempregados -, os sentimentos que o momento desperta, bem como as ações que essa vivência enseja - haja vista que uma vivência é orientada para a superação desse conflito. Em especial para este estudo, no âmbito das práxis desdobradas da vivência do desemprego, serão focadas as ações que os trabalhadores realizam para sobreviver e superar essa situação.

Nesta pesquisa, considera-se os sentimentos como uma realidade subjetiva para quem os sente, mas também com origens objetivas, considerando que se trata de reações aos confrontos do sujeito diante da realidade. Também se transformam e são determinados histórico-culturalmente e se ligam organicamente aos pensamentos e ações que os sujeitos elaboram sobre o mundo (Machado, Facci, \& Barroco, 2011). As pesquisas relativas aos sentimentos dos desempregados, mesmo partindo de outras teorizações, têm identificado a predominância de solidão, fracasso, tristeza e angústia, que, na medida em que o tempo de desemprego se eleva, associam-se à manifestação de transtornos de ansiedade e depressão, bem como ao uso abusivo e à dependência do álcool e outras drogas (Andersen, 2014; Barros \& Moreira, 2015; Barros \& Oliveira, 2009; Buendía, 2010; Tumolo, 2002). Também são predominantes sentimentos de inutilidade e improdutividade, que redundam em sofrimentos psicológicos (Caleiras, 2015; Oliveira \& Mendes, 2014). Esses sentimentos, por sua vez, possuem uma forte mediação com a relação estabelecida diretamente com a família, podendo ser experimentados acolhimento e potencialização da ação, quando esse núcleo apoia o trabalhador, ou desencadeados sentimentos associados ao sofrimento, quando há uma pressão ou abandono por parte dos familiares (Leão et al., 2015).

Os sentidos do trabalho atribuídos pelos trabalhadores desempregados, por sua vez, evidenciam o aprofundamento de tendências comuns ao capitalismo. Isto é, comparadas aos estudos com assalariados, as investigações sobre essa temática com os desempregados retratam uma predominância dos sentidos relativos à característica financeira do trabalho, ressaltando a sua função instrumental/econômica - como atividade para obtenção de renda e garantia de sobrevivência -, bem como uma forma de ocupar e organizar a vida de maneira geral (Brief, Konovsky, Goodwin, \& Link, 1995; Bendassolli, Coelho-Lima, Pinheiro, \& Gê, 2016).

Quanto às crenças acerca das razões para estarem desempregados, algumas investigações evidenciaram que há predominância da autorresponsabilização dos trabalhadores desempregados por sua condição (Tumolo \& Tumolo, 2004). Tal justificativa passava por acreditar que se estava desempregado por causa da sua baixa escolaridade, insuficiente qualificação profissional, pouca experiência profissional, idade ou raça. Contudo, outros estudos (Gondim et al., 2010; Mylonas et al., 2016) têm evidenciado que o tipo de justificativa adotada estaria condicionada ao tempo no desemprego, pois os trabalhadores com maior tempo

\footnotetext{
${ }^{5}$ Aqui, compreende-se sentido do trabalho como uma unidade dialética entre sentido e significado, relativa aos processos pelos quais os sujeitos apropriam-se dos significados sociais (valores, crenças, ideias, conceitos, dentre outros elementos culturais) para organizar a sua práxis. Estes são metabolizados em sentidos pelo indivíduo em face do seu acúmulo biográfico (memórias, afetos, experiências etc.), bem como dos problemas concretos e imediatos apresentados pela sua vida cotidiana (Vygotsky, 1934/2009).
} 
nessa situação tenderiam a sair do plano individual para o societal ou fatalista de explicação da sua situação. Furtado (1999), por sua vez, ao tratar da consciência do trabalhador acerca da determinação do seu desemprego, já revelava uma heterogeneidade dessa compreensão entre os metalúrgicos desempregados.

Considerando o que os trabalhadores fazem diante do desemprego, é possível encontrar, na literatura, alguns caminhos típicos para garantir a sua sobrevivência, quais sejam: apoio financeiro da família, realização de trabalhos esporádicos (“bicos”) e trabalhos por conta própria. Além disso, o recurso à religiosidade é comum, como forma de suportar as incertezas e desesperanças produzidas na situação de desemprego. Para superar a situação de desemprego, e não só garantir a sua sobrevivência, os trabalhadores desempregados, geralmente, recorrem a saídas individuais. Assim, aqueles que possuem algum recurso financeiro, como poupança ou familiar que possa prover sustento, adiam a entrada na busca de um emprego em igual ou melhores condições do que o anterior; enquanto os sem tais recursos se lançam em trabalhos mais precários e piores do que o antecessor (Argolo \& Araújo, 2004; Bendassolli, Coelho-Lima, Carlotto, Nussle, \& Ferreira, 2015). Não se pode perder de vista que os enfrentamentos coletivos ao desemprego também são verificados na literatura desse campo, como o Movimento dos Trabalhadores Desempregados (Prette, 1990) e a Economia Solidária (Dal Magro \& Coutinho, 2006).

\section{Método}

Esta pesquisa constitui-se na primeira etapa do projeto de investigação denominado "Vivências dos trabalhadores desempregados: estratégias de sobrevivência, superação e significação do trabalho/desemprego", coordenado pelo Prof. Dr. Fellipe Coelho-Lima. Dessa forma, seu objetivo, dentro da lógica desse projeto, é realizar uma primeira caracterização de alguns aspectos da vivência desses trabalhadores desempregados.

\section{Caracterização dos participantes}

Considerando o objetivo desta pesquisa, os participantes eram moradores da cidade de Santa Cruz/RN. Esse município localiza-se à $118 \mathrm{~km}$ de Natal (capital do estado) e é a cidade polo da região do Trairi, que congrega mais outros quatorze municípios. Possui uma população estimada de 39.300 pessoas, sendo ela predominantemente urbana $(85,2 \%)$. Por ser uma cidade polo, tem como principais atividades econômicas o oferecimento de serviços diversos e ser a sede de variados órgãos públicos (IBGE, 2016).

Para a definição do número total de participantes da pesquisa, utilizou-se a saturação teórica, tomando como base os critérios definidos por Fontanella, Ricas e Turato (2008). Dessa forma, chegou-se à quantidade de 10 trabalhadores desempregados, sendo na décima entrevista o momento no qual não foram identificadas novas categorias dentro dos quatro eixos que guiaram a entrevista.

Como critérios de inclusão, adotou-se o conceito de desempregado do Departamento Intersindical de Estatística e Estudos Socioeconômicos (DIEESE, s. d.). Portanto, foram incluídas pessoas que não exerciam atividade remunerada, ou que exerciam de maneira informal, e procuravam emprego formal e aquelas que não exerciam nenhuma atividade, mas 
que desistiram de procurar. A partir da técnica de "bola de neve" (Vinuto, 2014), escolheu-se dez participantes de acordo com indicações sucessivas, estando aptas a participar aquelas pessoas que se confirmavam estar desempregada, residir em Santa Cruz e concordar em participar voluntariamente da pesquisa.

Essa estratégia de composição do grupo de participantes conseguiu captar pessoas com perfis sociodemográficos distintos - garantindo diversidade nas vivências retratadas -, ainda que não tenham sido mantidas proporções de acordo com a população de maneira geral. Dessa forma, foram entrevistadas sete mulheres e três homens, com idade média de 31,9 anos (idade mínima de 20 anos e máxima de 55 anos). Mais comumente, possuíam como formação o ensino médio completo (seis casos), mas contou-se ainda com sujeitos com ensino fundamental completo e ensino superior completo. $O$ tempo de desemprego variou entre um mês e 20 anos, estando nove dos dez casos na faixa entre um mês e dois anos desempregados. Os participantes eram de profissões diversas, incluindo trabalhos técnicos sem exigência de formação específica e de nível superior.

\section{Procedimentos de coleta de dados}

Para a coleta de dados, foi utilizada entrevista semiestruturada (Minayo, 1996) organizada em torno de quatro eixos temáticos: crenças sobre o desemprego, sentidos atribuídos ao trabalho, sentimentos experienciados na situação de desemprego e formas de lidar com o desemprego (sobrevivência e superação dessa situação). A escolha desses eixos se justifica por duas razões. A primeira, como já abordado na seção anterior, é que essas dimensões trazem elementos acerca da vivência dos sujeitos na situação de desemprego. Afinal, trata tanto da forma como eles metabolizam essa situação dramática em suas consciências - revelada por meio dos sentidos do trabalho, crenças sobre o desemprego e sentimentos experienciados - como do modo que tal apreensão se desdobra nas ações sobre essa situação - representado pelas estratégias que adotam para sobreviver e superar o desemprego.

A segunda razão é que esses eixos acabam por agregar as principais questões que a Psicologia brasileira tem abordado junto à questão do desemprego. A comparação dos resultados construídos nessas investigações, que foram produzidas em capitais, com a presente pesquisa, realizada em uma cidade interiorana, pode potencializar a apreensão das diferenças de vivências em cada um desses contextos. É importante resgatar que, dentro da perspectiva materialista-histórico-dialética - da qual as teorizações vygotskyanas são herdeiras -, a apreensão da consciência dos sujeitos apenas é possível considerando as condições materiais às quais estão submetidos (Marx \& Engels, 1932/2015). Por isso é que se parte do pressuposto que a localização dos sujeitos em uma cidade com dinâmica econômico-social qualitativamente diferente das capitais pode resultar em formas de consciência - e práxis - distintas entre esses trabalhadores.

As entrevistas foram realizadas em locais escolhidos pelos próprios entrevistados e ocorreram, na maioria das vezes, nas suas próprias residências. Os encontros aconteceram nos meses de outubro e novembro de 2016, sendo realizado apenas um momento com cada um dos participantes, de duração média de 50 minutos. As entrevistas foram gravadas, de acordo com a anuência dos participantes, e posteriormente transcritas.

Os sujeitos foram convidados a participar voluntariamente da pesquisa, sendo explicados previamente o objetivo, riscos, benefícios, confidencialidade das informações e 
estratégias para minimização de qualquer consequência negativa que a pesquisa pudesse ter. Todas as informações estavam contidas no Termo de Consentimento Livre e Esclarecido que foi entregue aos convidados, sendo a participação confirmada apenas após a sua assinatura. Todos os sujeitos contatados aceitaram participar da pesquisa.

\section{Procedimentos de análise de dados}

A análise dos dados pretendeu apreender, a partir das singularidades representadas pelas vivências comunicadas por cada participante, a expressão da particularidade determinante da situação de desempregado, que media a sua relação com a universalidade da qual participam esses sujeitos (Pasqualini \& Martins, 2015). Em outros termos, a análise empreendida teve por finalidade apreender as particularidades de fundo, como a localização socioespacial da vida em cidade interiorana, que mediam a vivência singular dos participantes com a universalidade de estar situado em uma sociedade capitalista e, portanto, que pressupõe a existência do desemprego. Para tanto, pretendeu-se identificar, nessas singularidades, não a normalidade da sua expressão, mas os traços essenciais presentes nessas vivências (Ilienkov, 1973/2013). Portanto, a importância dada a uma ou outra fala não foi apenas pela quantidade de sujeitos que as expôs: mesmo falas pontuais podem revelar aspectos dessa particularidade que, nas demais vivências, não se expressaram.

De maneira operacional, a vivência singular dos sujeitos foi captada por meio das entrevistas. Para caracterizar essas vivências e apreender os traços essenciais que expressam a particularidade que as determina, foi necessário organizar o conteúdo relativo a elas. Para tanto, os textos produzidos foram lidos exaustivamente, no esforço de criar e recriar os códigos que permitissem sintetizar os conteúdos levantados por cada participante para os quatro eixos da entrevista. Esse processo de criação de codificações se assemelhou aos produzidos, geralmente, em análises qualitativas (Bauer, 2000). Como se trata de apreender a singularidade, não se elencou codificações a priori, ainda que se parta da consideração teórica de que a vivência pode ser expressa nos quatro eixos organizadores da entrevista.

Após essa organização do material, operou-se uma análise em dois ciclos subsequentes: intracasos e intercasos. No primeiro, considerando-se apenas cada caso em específico, com o objetivo de caracterizar a singularidade de cada vivência dos sujeitos diante do desemprego. No segundo, os conteúdos de cada eixo foram comparados entre si, a fim de apreender os traços essenciais que expressariam a particularidade dessas singularidades, que estavam situadas histórico-socialmente em uma cidade interiorana de um país periféricos latino-americano, resgatando a universalidade de ser uma vivência na etapa tardia do capitalismo. Para efeitos deste artigo, a exposição que se segue irá apresentar o conteúdo advindo desse segundo momento de análise.

\section{Resultados e discussões}

A partir das entrevistas realizadas e da dupla análise dos textos gerados, foi possível construir o Quadro 1, o qual será mais bem discutido ao longo desta seção. Os nomes relativos aos participantes apresentados neste texto são fictícios. 
Quadro 1: Categorias extraídas da análise das entrevistas

\begin{tabular}{|c|c|c|}
\hline Eixo & Categoria & Participantes \\
\hline \multirow{3}{*}{$\begin{array}{l}\text { Crenças sobre o } \\
\text { desemprego }\end{array}$} & Situação da economia nacional & Larissa, Pedro, Mariana, Laura e Joana \\
\hline & Busca de emprego melhor & Luiza, Patrícia, Paulo e Fabrício \\
\hline & Demandas familiares & Larissa \\
\hline \multirow{4}{*}{$\begin{array}{l}\text { Sentidos do } \\
\text { trabalho }\end{array}$} & Sobrevivência & $\begin{array}{l}\text { Luiza, Larissa, Paulo, Magda, Fabrício, Mariana, } \\
\text { Laura, Pedro }\end{array}$ \\
\hline & Status social & Pedro \\
\hline & Contribuição com a sociedade & Paulo e Laura \\
\hline & Ocupação do tempo & Luiza e Mariana \\
\hline \multirow{2}{*}{$\begin{array}{l}\text { Sentimentos } \\
\text { relacionados ao } \\
\text { desemprego }\end{array}$} & Negativos & $\begin{array}{l}\text { Mariana, Luiza, Patrícia, Larissa, Paulo, Magda, } \\
\text { Pedro, Laura, Joana }\end{array}$ \\
\hline & Positivos & Mariana, Patrícia, Paulo, Fabrício e Mariana \\
\hline \multirow{7}{*}{$\begin{array}{l}\text { Formas de lidar } \\
\text { com o desemprego }\end{array}$} & Distribuição de currículos & Luiza, Pedro e Laura \\
\hline & Realização de capacitação & $\begin{array}{l}\text { Patrícia, Larissa, Paulo, Magda, Fabrício, Mariana e } \\
\text { Laura }\end{array}$ \\
\hline & Desistência de busca de emprego & Patrícia e Larissa \\
\hline & Busca de vagas & Mariana \\
\hline & Realização de trabalhos informais & Luiza, Larissa, Laura, Magda, Fabrício e Mariana \\
\hline & Auxílio da família & Luiza, Larissa, Patrícia, Paulo e Laura \\
\hline & Uso de políticas públicas & Laura e Pedro \\
\hline
\end{tabular}

\section{Crenças sobre o desemprego}

Nesta investigação, ao indagar sobre o que os participantes acreditavam ser o motivo de estarem desempregados, obteve-se três subcategorias distintas.

A primeira delas é a responsabilização da situação econômica nacional pelo seu atual estado de desemprego. Para eles, a crise econômica pela qual o Brasil passava, em 2016, tinha sido responsável pela sua demissão e a sua dificuldade em retornar ao mercado formal de trabalho. Eles se valeram da sua experiência concreta, como foi o caso de Pedro e Mariana: ambos participaram de um processo de demissão em massa, justificado, pela empresa, como resultado da redução dos lucros no período de crise. A segunda categoria refere-se à busca por um emprego melhor: quatro dos participantes pediram demissão de seu antigo trabalho em busca de um novo, com melhores condições laborais. A terceira, refere-se à necessidade de permanecer fora do mercado de trabalho para dedicar-se a criação de uma filha recém-nascida. 
O que se constata é que, diferentemente do apontado em outros estudos (Tumolo \& Tumolo, 2004), não há um predomínio de autoculpabilização pela situação de desemprego. Os achados desta pesquisa acabam por corroborar os cenários que vêm sendo traçados por Bendassolli, Gondim e Coelho-Lima (2015), Furnham (1982), Furtado (1999), Gondim et al. (2010) e Mylonas et al. (2016), nos quais os trabalhadores desempregados compreendem que o desemprego é muito mais um problema social do que uma deficiência pessoal.

\section{Sentidos atribuídos ao trabalho}

O segundo eixo investigado, nesta pesquisa, refere-se aos sentidos atribuídos ao trabalho. Neste tópico, quatro categorias puderam ser levantadas.

A categoria hegemônica foi a denominada "sobrevivência". Nela, os sujeitos relataram que o trabalho é, para eles, predominantemente, uma forma de sobreviver, de garantir o seu dinheiro e de prover a vida da sua família. Falas como a de Luiza - "[o trabalho tem uma] importância central, afinal, dependo dele para sobreviver" -, Larissa - "É o que leva o sustento para as famílias" - e de Fabrício - "É o trabalho que me mantém, que me sustenta, que me dá oportunidades na vida" - exemplificam bem o conteúdo dessa categoria.

As outras três categorias encontradas são mais restritas e foram evocadas em segundo plano pelos entrevistados. Uma delas se refere a significação de que o trabalho é uma forma do sujeito contribuir com a sociedade e se sentir socialmente útil, como exemplifica Paulo, "Acredito que trabalho é fazer alguma função pelo outro, pela sociedade, pelo crescimento da humanidade, seja em pequena ou grande escala". A terceira categoria identificada foi a significação do trabalho como forma de ocupação do tempo. Por fim, a quarta categoria resgata a contribuição positiva do trabalho para o status social do trabalhador, ou, como afirma Pedro, "as pessoas que trabalham são mais valorizadas na sociedade".

As categorias encontradas neste eixo não destoam do que foi apontado em outros estudos (Álvaro et al., 2012; Harpaz \& Meshoulam, 2004; Peixoto \& Borges, 2015). Há indícios de que o trabalho, nos mais diversos estratos da classe trabalhadora, é considerado, prioritariamente, como uma fonte de renda. Uma explicação possível para essa recorrência é a própria conformação concreta do trabalho no capitalismo, como destacado por um dos participantes:

É a fonte de renda, o que quer dizer uma espécie de documento do ser humano. No mundo da economia capitalista, quem não tem dinheiro não tem identidade, não tem nada, não é à toa que o trabalho é visto como uma necessidade (Paulo).

Dessa forma, para a classe trabalhadora, apenas é possível ter acesso aos bens produzidos na sociedade capitalista por meio da venda da sua força de trabalho e obtenção de alguma renda, constituindo-se, assim, um processo de alienação do produtor do seu trabalho, algo típico desse modo de produção (Marx, 1867/2013). Nessa direção, assim como outros estudos sobre sentido e significado do trabalho já revelaram (Bendassoli et al., 2016; Brief et al., 1995), aparentemente essa significação ganha mais força entre os desempregados, por ser negado a ele o acesso à renda via trabalho. 


\section{Sentimentos relacionados ao desemprego}

Neste eixo, foi possível levantar duas categorias que reúnem o conteúdo das entrevistas: sentimentos negativos ou positivos. Tal valoração sobre o tipo de sentimento experienciado foi realizada pelo próprio entrevistado.

Seguindo tendências identificadas por outros estudos (Ackermann et al., 2005; Andersen, 2014; Argolo \& Araújo, 2004; Barros \& Oliveira, 2009; Buendía, 2010; Silva, 2012; Tumolo, 2002), houve predominância de sentimentos negativos. Os participantes nomearam diversos desses sentimentos, como desamparo (Luiza), tristeza (Patrícia e Joana), incômodo (Paulo e Joana), não se sentir bem (Magda), saudades de trabalhar (Pedro), se sentir péssimo (Pedro) e desespero (Laura). Alguns relatos descrevem em detalhes a vivência desses sentimentos, destacando o processo de intensificação dos sentimentos negativos proporcionalmente ao tempo de desemprego, como no seguinte:

Um frio no coração. Foi horrível, porque eu pensei assim: meu Deus, estou desempregada. $O$ que vou fazer agora? Será que vou conseguir outro emprego? Aí, você começa a ir em busca de trabalho de novo e recebe um não. É muito difícil (Joana).

É importante destacar que, para os participantes, há diversos aspectos específicos da situação do desemprego que geram tais sentimentos negativos, sendo elas a falta de renda (Patrícia, Larissa e Paulo), a ausência da atividade laboral em si (Magda e Pedro), quebra da rotina anterior (Joana), retirada de um ambiente de trabalho e de relações sociais prazerosas (Pedro) e falta de perspectiva de um novo emprego (Laura e Joana).

A segunda categoria apresenta outra face do desemprego, já que revela alguns sentimentos positivos despertados nessa situação, quais sejam: alívio (Patrícia, Paulo e Mariana) e expectativa positiva (Fabrício). Nesses quatro casos, esses sentimentos foram despertados por se desejar um emprego com condições melhores do que o anterior e, portanto, experienciou-se alívio e expectativa por não estar em uma atividade laboral indesejada. Dessa forma, tais dados concordam com pesquisas anteriores (Ezzy, 1993; Graetz, 1993), as quais destacam que a saída de empregos precários pode gerar efeitos positivos ao trabalhador.

Ainda que o desemprego possa gerar diversas experiências afetivas negativas, notadamente por retirar o trabalhador do seu lugar circunscrito no capitalismo, pelo qual acabam se submetendo a trabalhos precarizados - principalmente considerando que são oriundos de cidades interioranas de pequeno porte -, contraditoriamente, a situação de desemprego também despertou sentimentos positivos. Da mesma forma, revelou-se que, mesmo em tais situações e mesmo o trabalho sendo reduzido pela própria relação produtiva em uma fonte de renda, ainda persistem aspectos humanizadores do trabalho, como o estabelecimento de relações sociais positivas com os colegas de trabalho.

\section{Formas de lidar com o desemprego}

Como já aludido anteriormente, para apreensão da práxis desdobrada da vivência dos trabalhadores desempregados, foi abordada a forma como lidam com o desemprego. Mais especificamente, as ações que realizam para sobreviver e para superar essa situação, sendo ambas apresentadas a seguir. 
Quanto à sobrevivência dos participantes, três estratégias são utilizadas. A primeira delas é a realização de trabalhos informais. Nessa forma de trabalho estão inclusos: venda de peças íntimas (Luiza), de perfumaria (Joana), produção de artesanato (Larissa), realização de serviços domésticos como diarista (Magda), realização de trabalhos esporádicos (Fabrício e Laura) e auxílio a familiares em seus negócios (Mariana). Esses participantes relataram que realizam esses trabalhos como forma de complementar a sua renda ou a da família. A segunda estratégia de sobrevivência mais comum é contar com o auxílio financeiro da família, principalmente de suas mães (Luiza e Patrícia). A terceira estratégia, com menor recorrência, é a utilização das políticas públicas. Mais especificamente, foram registrados dois casos nessa categoria, relatando o uso de duas políticas distintas: o recurso ao Bolsa Família, por parte de Laura; e o uso do seguro desemprego, por Pedro. Ainda é característica, como forma de sobrevivência, a associação de mais de uma estratégia.

De maneira geral, esse quadro reproduz o que outros estudos têm identificado como forma de sobreviver ao desemprego (Bendassolli et al., 2015; Couyoumdjian \& Larroulet, 2009; Sala, 2011; Tumolo, 2002). Por um lado, os trabalhadores nessa situação são lançados nos mais diversos tipos de trabalho informal existente; e, por outro, ocorre uma socialização dos prejuízos financeiros causados pelo desemprego para a família, a qual já não possui renda elevada. Enquanto isso, as políticas públicas de apoio aos trabalhadores nessa situação - representadas pelo seguro desemprego - possuem um papel reduzido na mitigação dos efeitos negativos do desemprego.

Quanto às estratégias para superação do desemprego, elas se concentraram em distribuição de currículos (três casos), realização de capacitação (sete casos) e busca de vagas abertas (um caso). Assim, os participantes desta pesquisa reproduzem as técnicas mais comuns para procura de um novo emprego empreendidas pelos trabalhadores brasileiros, mesmo não sendo as estratégias mais efetivas. Além disso, se valeram apenas de iniciativas individuais e não coletivas de superação do desemprego. Assim, mesmo predominando compreensões do desemprego como um problema social, valem-se de ações individuais para lidar com essa situação. É compreensível que se utilizem desse expediente, principalmente diante do discurso reproduzido na mídia e pelas empresas de que, quanto mais capacitado, mais facilmente o trabalhador será empregado novamente (Balassiano, Seabra, \& Lemos, 2005). Contudo, tal pressuposto é falacioso, quando se está em um cenário de crise econômica, no qual a própria quantidade de vagas é escassa (Ramos, Lobo, \& Anze, 2015).

Uma segunda consideração é quanto à ausência do recurso à agência de emprego, seja pública, seja privada. Em outras pesquisas (Bendassolli et al., 2015; Guimarães, 2009a), mesmo não sendo a estratégia mais utilizada e sendo uma com menor efetividade, ainda se fazia presente o recurso a tais agências. Uma possível explicação para isso é a ausência ou pouca participação das agências de emprego no cenário da região. Isso indicaria uma deficiência da política pública de trabalho de intermediação de mão de obra em conduzir esse tipo de processo nos municípios e interiores dos estados.

Por último, ainda chama atenção a ausência de uma das estratégias mais efetivas na busca de um novo trabalho (Guimarães, 2009b), o recurso às redes de contato pessoal. Isto é, os participantes desta pesquisa não relataram solicitar auxílio de familiares, parentes e amigos para a indicação de um novo emprego. 


\section{Vivência dos trabalhadores desempregados em uma cidade interiorana}

A partir dos dados apresentados, pode-se sistematizar as semelhanças e diferenças das vivências de desemprego dos trabalhadores residentes na cidade interiorana escolhida para o estudo em questão dos de outras regiões.

A população estudada compartilha com as de outras regiões do país a predominância de afetos ambíguos quanto ao desemprego. Ao mesmo tempo em que há o relato de diversos afetos negativos relacionados a sua situação, também são evocados sentimentos positivos, principalmente motivados pela saída de um emprego precário que gerava sofrimento no participante. Também se assemelham as significações produzidas em torno do trabalho, quais sejam, equivalê-lo à sobrevivência, contribuição para a sociedade e ocupação do tempo, bem como o recurso a saídas individuais para o desemprego (busca por formação complementar).

Alguma divergência é identificada quanto às estratégias de sobrevivência e superação. No primeiro caso, o que se destaca é a prioridade de explicações externalistas sobre o desemprego (e não autoculpabilizações) e, no segundo, destaca-se a pouca participação das políticas públicas como forma de enfrentar o desemprego - apesar de tal constatação também estar presente nas pesquisas realizadas em capitais, o que se identificou nesta investigação foi o aprofundamento desse quadro.

Resgatando a base teórica da Psicologia Histórico-Cultural, apresentada no início deste artigo, pode-se apontar algumas explicações possíveis para os dados encontrados. Quanto às aproximações, elas estão relacionadas principalmente ao modo como se interpreta e se sente a realidade (afetos, significados e crenças). Esse compartilhamento com os achados em capitais pode ser explicado por dois elementos dialeticamente interconectados. O primeiro, é o compartilhamento de certa cultura em torno do trabalho - esse comparecendo como particularidade que medeia a relação entre as vivências singulares e a universalidade do modo de produção capitalista. Os sentidos comunicados pelas pessoas são oriundos de um metabolismo dos significados socialmente compartilhados com as vivências e arcabouço que possuem (Vygotsky, 1934/2009). Portanto, não é incomum que sentidos semelhantes aos encontrados em outras regiões do Brasil (e do mundo) também sejam materializados pelos trabalhadores participantes desta pesquisa. A cidade em questão possui acesso consolidado à Internet, mídia de massa, bem como instituições educacionais que atraem pessoas de outras regiões, o que permite a permeabilidade a valores culturais também presentes em outras regiões. Ademais, o que os relatos permitem evidenciar é que compartilham tanto significações como processos de precarização do trabalho. Tal confronto com a realidade objetiva é outra condição para a elaboração das vivências pelos sujeitos (Vygotsky, 1934/2009). Com isso, é possível explicar fenômenos como a ambiguidade nos sentimentos sobre o desemprego, haja vista que, se, por um lado, perde-se o meio de sobrevivência, por outro, também há satisfação em sair de um trabalho que gera sofrimento.

Em suma, tais semelhanças identificadas nas vivências dos trabalhadores em cidades mais e menos desenvolvidas economicamente pode ser explicada por ambas estarem inseridas, mesmo que de forma desigual, no sociometabolismo capitalista - a universalidade que compartilham - e na cultura e organização do trabalho dele emanados - as particularidades que medeiam as singularidades de suas vivências. 
Quanto às diferenças encontradas - o pouco recurso às políticas públicas e aos círculos de familiares e amigos como estratégia de sobrevivência e de enfrentamento -, é possível inferir que nelas se revela a particularidade da vivência desses trabalhadores, a condição material a qual estão submetidos por estarem em uma cidade com menor desenvolvimento econômico. Como comentado no início do artigo, nessas localidades, além da reduzida rede de empresas e oportunidades de trabalho, também há uma menor rede socioassistencial provida pelo Estado. Portanto, o recurso às políticas públicas não figura como opção possível na vivência dos trabalhadores, nem para a redução dos efeitos negativos do desemprego, nem para a busca por um novo trabalho. Considerando que uma das principais políticas públicas de trabalho é o seguro-desemprego, e o mesmo só é acessado por aqueles oriundos de um emprego formal, também é retrato da precariedade do trabalho nessas regióes menos desenvolvidas.

Igualmente, a aparente contradição entre os participantes compreenderem o desemprego como determinado socialmente, mas adotarem ações individuais para buscar sua superação, pode ser explicada por, ao menos, duas determinações (particularidades) específicas. A primeira delas, seria a ausência em suas consciências - e, possivelmente, no seu contexto cultural - de alternativas coletivas concretas e viáveis. Chama atenção que, mesmo existindo cooperativas de produção na região, nenhum dos participantes as considerou como opção. Um segundo determinante pode ser a predominância de valores individualistas, caraterísticos dos elementos culturais da atual etapa do capitalismo, que limitam a elaboração de alternativas coletivas por esses desempregados.

Com relação ao pouco uso dos contatos pessoais para a busca de um novo trabalho, pode-se considerar também a configuração sociocultural da própria cidade como explicação para esse fenômeno. Diferente dos grandes centros, em que o contato com as pessoas responsáveis pela decisão de contratação ocorre de forma mediada, a configuração de uma cidade interiorana com empreendimentos de menor porte permite que os candidatos abordem diretamente os proprietários dos empreendimentos. Dessa forma, a abordagem direta nas empresas, por meio da entrega de currículo apareceria como alternativa mais viável para a solução da situação conflitiva do desemprego na vivência do trabalhador.

\section{Considerações finais}

Os resultados apresentados neste artigo desenharam um cenário da vida do trabalhador desempregado em um município do interior do estado semelhante aos obtidos por outros estudos que investigaram esse fenômeno em capitais e grandes centros. Neste estudo, apenas pequenas diferenças foram constatadas, focadas, principalmente, na participação reduzida das políticas públicas e dos contatos pessoais como estratégias de enfrentamento e sobrevivência ao desemprego.

Haver mais semelhanças do que diferenças entre as vivências dos trabalhadores desempregados em cidades mais desenvolvidas/capitais e os oriundos de cidades com menor desenvolvimento/interioranas pode evidenciar, como debatido, que há um compartilhamento tanto de valores culturais referentes ao trabalho, como de características semelhantes de precariedade do trabalho. Isso é possível por essas cidades também estarem, de forma diferente 
e desigual daquelas com maior desenvolvimento, inseridas de alguma forma no modo de produção capitalista, compartilhando particularidades dessa universalidade.

Por outro lado, tal constatação pode indicar a necessidade de estudos que aprofundem a análise acerca de aspectos específicos dessas vivências. Pesquisas focalizando tanto as dimensões das vivências aqui utilizadas como em outras - como a história de vida dos trabalhadores desempregados, a significação que produzem sobre o desemprego ou, mesmo, a forma como elaboram as estratégias de enfrentamento e sobrevivência -, podem ajudar na compreensão das particularidades dessas vivências.

De todo modo, os resultados e discussões aqui apresentados, somados a outros estudos sobre a questão da vida dos desempregados, apontam uma vivência cada vez mais degradada para esses sujeitos. Diante de tal cenário, são importantes pesquisas nessa direção, que revelem as particularidades da barbárie do desemprego para os diversos grupos de homens e mulheres que estão nessa situação e, muito mais, fundamentem ações que promovam a emancipação desses sujeitos do sociometabolismo que se revela dia após dia, contraditoriamente, mais desumanizador.

\section{Referências}

Ackermann, K., Amaral, M. A., Silva, J. C. B., Geraldes, A. L., Lima, T. N., Lombardi, M., Júnior, Mendes, A., \& Scandiucci, G. (2005). O desemprego do tempo: narrativas de trabalhadores desempregados em diferentes ambientes sociais. Cadernos de Psicologia Social do Trabalho, 8, 1-27.

Álvaro-Estramiana, J. L., Gondim, S. M. G. G., Garrido-Luque, A., Luna, A. F., \& Dessen, M. C. (2012). Desempleo y bienestar psicológico en Brasil y España: Un estudio comparativo. Revista Psicologia: Organizações e Trabalho, 12 (1), 1-12.

Andersen, S. H. (2014). Unemployment and subjective well-being: a question of class? Work and Occupations, 41 (2), 3-25.

Antunes, R. (1999). Os sentidos do trabalho: ensaio sobre a afirmação e a negação do trabalho. São Paulo: Boitempo.

Argolo, J. C. T. \& Araújo, M. A. D. (2004). O impacto do desemprego sobre o bem-estar psicológico dos trabalhadores da cidade de Natal. Revista de Administração Contemporânea, 8 (4), 161-182.

Balassiano, M., Seabra, A. A. D., \& Lemos, A. H. (2005). Escolaridade, salários e empregabilidade: tem razão a teoria do capital humano? Revista de Administração Contemporânea, 9 (4), 31-52.

Barros, C. A. \& Oliveira, T. L. (2009). Saúde mental de trabalhadores desempregados. Revista Psicologia Organizações e Trabalho, 9 (1), 86-107.

Barros, R. M. \& Moreira, A. S. (2015). Desemprego, autoestima e satisfação com a vida: estudo exploratório realizado em Portugal com beneficiários do Rendimento Social de Inserção. Revista Psicologia Organizações e Trabalho, 15 (2), 146-156.

Bauer, M. W. (2000). Classical content analysis: a review. In M. W. Bauer \& G. Gaskell (Eds.), Qualitative researching with text, image and sound: a practical handbook for social research (pp. 131-151). Londres: Sage.

Bendassolli, P. F., Coelho-Lima, F., Carlotto, M. S., Nussle, F. S., \& Ferreira, I. M. (2015). Estratégias utilizadas pelos trabalhadores para enfrentar o desemprego. Revista Colombiana de Psicologia, 24 (2), 347-362.

Bendassolli, P. F., Gondim, S. M. G., \& Coelho-Lima, F. (2015). Attributions of causes for unemployment by unemployed workers. Análise Psicológica, 33, 153-164.

Bendassolli, P. F, Coelho-Lima, F, Pinheiro, R. A., \& Gê, P. A. S. (2016). The meaning of work during short-term unemployment. Psicologia: Teoria e Pesquisa, 32 (1), 123-132. 
Brief, A., Konovsky, M., Goodwin, R., \& Link, K. (1995). Inferring the meaning of work from the effects of unemployment. Journal of Applied Social Psychology, 25, 693-71.

Buendía, J. (2010). El impacto psicológico del desempleo. Murcia: Servicio de Publicaciones.

Caleiras, J. (2015). Para lá dos números: as consequências pessoais do desemprego. Coimbra: Leya.

Carmo, F. M. \& Jimenez, S. V. (2013). Em busca das bases ontológicas da psicologia de Vygotsky. Psicologia em Estudo, 18 (4), 621-631.

Coelho-Lima, F., Costa, A. L. F., \& Bendassolli, P. F. (2013). A produção científica da psicologia brasileira acerca do desemprego. Universitas Psychologica, 12 (4), 1283-1299.

Couyoumdjian, J. P. \& Larroulet, C. (2009). Entrepreneurship and growth: a latin american paradox? The Independent Review: A Journal of Political Economy, 14 (1), 81-100.

Dal Magro, M. L. P. \& Coutinho, M. C. (2006). Os sentidos do trabalho para sujeitos inseridos em empreendimentos solidários. Tese de doutorado, Programa de Pós-Graduação em Psicologia, Universidade Federal de Santa Catarina, Florianópolis.

Delari Jr, A. (2011). Sentidos do "drama" na perspectiva de Vigotski: um diálogo no limiar entre arte e psicologia. Psicologia em Estudo, 16 (2), 181-197.

DIEESE (s. d.). Sistema PED: metodologia utilizada. São Paulo: DIEESE.

Ezzy, D. (1993). Unemployment and mental health: a critical review. Social Science and Medicine, 37, 41-52.

Fontanella, B. J. C., Ricas, J., \& Turato, E. R. (2008). Amostragem por saturação em pesquisas qualitativas em saúde: contribuições teóricas. Cadernos de Saúde Pública, 24 (1), 17-27.

Furnham, A. (1982). Explanations for unemployment in Britain. European Journal of Social Psychology, 12, 335-352.

Furnham, A. (2013). The psychology of unemployment: Laying off people in a recession. In A. G. Antoniou \& C. L. Cooper (Eds.), The psychology of the recession on the workplace (pp. 155-175). Glos/Massachusets: Edward Elgar.

Furtado, O. (1999). Globalização e desemprego: um debate sobre o fim do emprego. Revista da ESPM, 6, 9-14.

Gondim, S. M. G., Álvaro, J. L., Luna, A. D. F., Oliveira, T., \& Souza, G. C. D. (2010). Atribuições de causas ao desemprego e valores pessoais. Estudos de Psicologia (UFRN), 15 (3), 309-317.

Graetz, B. (1993). Health consequences of employment and unemployment: longitudinal evidence for young men and women. Social Science and Medicine, 36, 715-724.

Guimarães, N. (2009a). Desemprego e procura de trabalho: mecanismos e percepções. In N. Guimarães (Org.), Desemprego, uma construção social: São Paulo, Paris e Tóquio (pp. 67-86). Belo Horizonte: Argvmentvm.

Guimarães, N. (2009b). A força dos contatos pessoais. In N. Guimarães (Org.), À procura de trabalho: instituições do mercado e redes (pp. 175-198). Belo Horizonte: Argvmentvm.

Harpaz, I. \& Meshoulam, I. (2004). Differences in the meaning of work in Israel: workers in high-tech versus traditional work industries. Journal of High Technology Management Research, 15 (2): 163-182.

Harvey, D. (2011). O enigma do capital: e as crises do capitalismo. São Paulo: Boitempo.

Ilienkov, E. V. (2013). O universal. Revista Dialetus, 1 (2), 253-278. (Originalmente publicado em 1973)

IBGE (2016). Cidades. Recuperado de https://cidades.ibge.gov.br/v4/municipio/241120

IBGE (2019). Indicadores IBGE: Pesquisa nacional por amostra de domicílios contínua - primeiro trimestre de 2019. Brasília: IBGE.

Kahn, H. (2013). Unemployment and mental health. In A. G. Antoniou \& C. L. Cooper (Eds.), The psychology of the recession on the workplace (pp. 196-208). Glos/Massachusets: Edward Elgar.

Leão, I. B., Maldonado, E. H., Moura, P. B., Teruya, P. S., Araújo, A. K., Espíndola, G. M., Santos, L. G., \& Moura, L. H. (2006). Implicações psicossociais do desemprego para a consciência individual: manifestações no pensamento e emoção. Pesquisas e Práticas Psicossociais, 1 (2), 1-24. 
Leão, I. B., Souza, J. A. M., \& Silva, A. P. B. (2015). The consciousness of unemployed workers in Brazil analysed by social psychology. In: B. Mohan. (Org.), Construction of social psychology (149-158). Lisboa: InScience Press.

Lima, A. V. Q. \& Gomes, M. W. F. (2010). "Estou formado(a), e agora?": uma análise sobre o sofrimento psíquico de desempregados recém-formados em instituições de nível superior em São Luís-MA. Cadernos de Pesquisa, 17 (3), 37-46.

Machado, L. V., Facci, M. G. D., \& Barroco, S. M. S. (2011). Teoria das emoções em Vigotski. Psicologia em Estudo, $16(4), 647-657$.

Mandel, E. (1982). O capitalismo tardio: uma tentativa de explicação marxista. São Paulo: Nova Cultura. (Originalmente publicado em 1972)

Mandelbaum, B. P. H. \& Ribeiro, M. A. (2017). Desemprego: uma abordagem psicossocial. São Paulo: Edgard Blücher.

Marx, K. (2013). O capital: crítica da economia política. Livro I: o processo de produção do capital. São Paulo: Boitempo. (Originalmente publicado em 1867)

Marx, K. \& Engels, F. (2015). A ideologia alemã. São Paulo: Boitempo. (Originalmente publicado em 1932)

Minayo, M. C. S. (1996). Pesquisa social: teoria, método e criatividade. Petrópolis, RJ: Vozes.

Moyano-Díaz, E., Gutiérrez Peña, D., Zúñiga Cabrera, K., \& Cornejo, F. A. (2013). Employees and unemployed, causal attributions and subjective well-being. Psicologia $\mathcal{F}$ Sociedade, 25, 440-450.

Mylonas, K., Furnham, A., Alvaro, J. L., Papazoglou, S., Divale, W., Cretu, R. Z., Grad, H., Gondim, S. M. G., Leblebici, C., Filus, A., Moniz, A., Mitsostergiou, A., Kyvetou, G., Konstantinidis, E., \& Boski, P. (2016). Explanations of unemployment: an eight-country comparison. International Journal of Academic Research in Business and Social Sciences, 6 (9), 344-361.

Nogueira, V. M. R. (2001). Estado de bem-estar social: origens e desenvolvimento. Revista Katálysis, 5, 89-103.

Oliveira, J. \& Mendes, A. (2014). Sofrimento psíquico e estratégias defensivas utilizadas por desempregados: contribuições da psicodinâmica do trabalho. Temas em Psicologia, 22 (2), 389-399.

Pasqualini, J. C. \& Martins, L. M. (2015). Dialética singular-particular-universal: implicações do método materialista dialético para a psicologia. Psicologia Eु Sociedade, 27 ( 2), 362-371.

Peixoto, T. P. \& Borges, L. O. (2015). The metals sector: labor union relations, motivation, and meanings of Work. Revista Colombiana de Psicología, 24 (1), 165-181.

Prestes, Z. \& Tunes, E. (2012). A trajetória de obras de Vigotski: um longo percurso até os originais. Estudos de Psicologia (Campinas), 29 (3), 327-340.

Prette, A. D. (1990). Movimentos sociais em uma perspectiva psicológica social: o movimento de luta contra o desemprego. Tese de Doutorado, Universidade de São Paulo, São Paulo.

Ramos, C. A., Lobo, V., \& Anze, V. R. (2015). A importância alocativa das políticas de emprego. Mercado de trabalho, 58 (21), 37-50.

Ribeiro, M. A. (2007). Psicose e desemprego: um paralelo entre experiências psicossociais de ruptura biográfica. Cadernos de Psicologia Social do Trabalho, 10 (1), 75-91.

Sala, G. (2011). Empleo y desempleo entre los adultos mayores argentinos. Documento de Trabajo, 7, 1852-1223.

Santa, F. D. \& Baroni, V. (2014). As raízes marxistas do pensamento de Vigotski: constribuições teóricas para a Psicologia Histórico-Cultural. Kínesis, 6 (12), 1-16.

Schmitz, H. (2011). Why are the unemployed in worse health? The causal effect of unemployment on health. Labour Economics, 18 (1), 71-78.

Silva, L. F. (2012). Estratégias de coping e bem estar subjetivo: estudo com trabalhadores desempregados. Dissertação de mestrado, Programa de Pós-Graduação Stricto Sensu em Psicologia, Pontifícia Universidade Católica de Goiás, Goiânia.

Toassa, G. \& de Souza, M. P. R. (2010). As vivências: questões de tradução, sentidos e fontes epistemológicas no legado de Vigotski. Psicologia USP, 21 (4), 757-779. 
Tumolo, L. M. S. (2002). As características da vivência das pessoas que se encontram desempregadas. Dissertação de mestrado, Universidade Federal de Santa Catarina, Florianópolis.

Tumolo, L. M. S. \& Tumolo, P. S. (2004). A vivência do desempregado: um estudo crítico do significado do desemprego no capitalismo. Espaço Acadêmico, 43, 1-13.

Veresov, N. (2016). Perezhivanie as a phenomenon and a concept: questions on clarification and methodological meditations. Cultural-Historical Psychology, 12 (3), 129-148.

Vinuto, J. (2014). A amostragem em bola de neve na pesquisa qualitativa: um debate em aberto. Temáticas, Campinas, 22 (44), 203-220.

Vygotsky, L. S. (2000). Psicologia concreta do homem. Educação Eु Sociedade, 21 (71), 23-44. (Originalmente publicado em 1986)

Vygotsky, L. S. (2009). A construção do pensamento e da linguagem. São Paulo: Martins Fontes. (Originalmente publicado em 1934)

\section{Endereço para correspondência:}

fellipecoelholima@gmail.com,matheus-rodrigo95@hotmail.com, katiane19_1@hotmail.com, anne.louyse@icloud.com

Recebido em: 09/03/2019

Revisado em: 05/08/2019

Aprovado em: 09/08/2019 